\title{
The Use of Protection for Sexually Transmitted Infections (STIs) and Unwanted Pregnancy among Norwegian Heterosexual Young Adults 2009
}

\author{
Bente Træen - Kirsten Gravningen
}

Published online: 5 March 2011

(C) The Author(s) 2011. This article is published with open access at Springerlink.com

\begin{abstract}
This paper explores the use and none-use of condoms among young heterosexual adults in Norway. To what extent do young heterosexuals use condoms and other types of contraception, and in which context does the use take place? What are the motives underlying both use and non use of condoms? The results are based on a 2009 national web panel survey among 16-24 year-olds in Norway $(n=871)$. Most respondents reported having met their most recent sex partner via friends or family, and $62 \%$ referred to the sex partner as a sweetheart. One out of two claimed they had not used condoms during the first sexual intercourse with this partner. A factor analysis revealed 2-D of motivation for not using condoms, referred to here as 'Fear of Suspicion' and 'Mutual Trust'. Multiple linear regression analysis revealed that, when controlled for gender, age, and number of sex partners in one's life, 'Mutual Trust' had a statistically significant relationship to coital frequency and the number of years coitally active. None of the predictor variables had a statistically significant relationship with "Fear of Suspicion". The most commonly reported motives for the most recent sexual intercourse were having been 'sexually aroused' and 'in love'. A total of 56\% reported using hormonal contraception, while $20 \%$ used condoms. The most important reasons for not using condoms were: 'used other contraception', 'did not worry about STIs', 'more pleasurable without', 'had none available', and 'unprepared for intercourse'. The most important reasons for condom use were to 'avoid pregnancy', 'avoid STIs', and 'avoid HIV'.
\end{abstract}

Keywords Condoms - STI protection - Motives · Adolescents · Norway

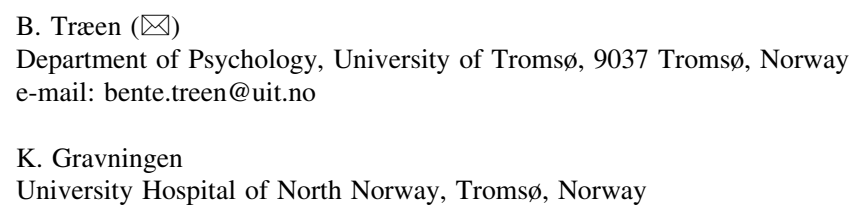




\section{Introduction}

The study of use of protection against sexually transmitted infections (STI), including HIV/AIDS, is of significant interest to society. However, in Norway 2002 it was concluded that after 2-3 decades of healthcare campaigns to prevent STI and HIV/AIDS, few behavioural changes in condom use had occurred (Træen et al. 2002, 2003a). Since 2002 new preventive healthcare initiatives have been implemented to increase the use of both STI protection and contraception to prevent unwanted pregnancy and abortion. In regards to STI protection, the Directorate of Health has developed a program that gives condoms to adolescents free of charge (Agenda 2008). The number of free condoms handed out to adolescents and groups of the population at particular risk for STIs (e. g. men who have sex with men) increased from 400,000 in 1999 to approximately 2.5 million in 2007. The sales statistics for condoms also showed an increase from 1999 to 2008. Regarding protection against unwanted pregnancy, emergency contraception can now be obtained without a prescription from a doctor. Furthermore, from 2002 to 2005 persons from the age of 15-19 had access to free hormonal contraception through any doctor, as well as nurses and midwives working at public health clinics for adolescents. Since 2006 contraception is no longer given for free, however, it is subsidized for people under the age of 25. According to the Directorate of Health this does not seem to have reduced the use of hormonal contraception among young women. In 2007, 64,000 women at the age of 16-19 received a prescription for oral contraception, compared to 62,000 in 2006 (The National Institute of Public Health 2008). The effects of these preventive healthcare measures on contraceptive behaviour seem positive (Øren et al. 2010). However, the effects of such measures on condom behaviour for STI protection are not known.

In the Norwegian and Nordic context, it is the responsible aspects of sexuality, rather than the passionate ones, that are idealised and socially accepted (Lewin 1987, 1990; Lewin et al. 2000; Træen et al. 2002, 2003b). If pregnancy is not the goal, heterosexual individuals are supposed to act responsibly and use contraception during intercourse. The use of contraception is not socially stigmatised and is regarded as a mutual responsibility (Helmius 1990; Lewin and Helmius 1983; Træen 1993; Træen and Hovland 1998).

Research has shown that, in order to understand the use of STI protection among young heterosexual adults, the use of protection against unwanted pregnancy must also be considered (Rosenthal et al. 1998; Stigum et al. 1995; Træen and Hovland 1998; Træen et al. 2002, 2003). The reason for this is that most intercourse, where the partners have very limited knowledge of each others' STI status, takes place within the context of a romantic sexual script. In a romantic heterosexual script, fertility is presumed and considered a "natural" quality of the sexual actors. In sharp contrast, assuming that one's sex partner has an STI is not considered "natural" at all (Træen 1993; Træen and Hovland 1998). Thus, love and infatuation are good news for the use of contraceptives, but not when it comes to STI protection. From a preventive healthcare perspective, the distinction between contraceptive and STI protective behaviour is important, as the different 
Table 1 Relationship with the most recent sex partner, by selected social background variables (percent)

\begin{tabular}{|c|c|c|c|c|c|c|c|}
\hline Weighted data & $N$ & $\begin{array}{l}\text { Permanent } \\
\text { partner/ } \\
\text { sweetheart }\end{array}$ & $\begin{array}{l}\text { Ex-partner/ } \\
\text { ex-sweetheart }\end{array}$ & $\begin{array}{l}\text { A friend I } \\
\text { only have } \\
\text { sex with }\end{array}$ & $\begin{array}{l}\text { Casual } \\
\text { contact }\end{array}$ & Other & Sign \\
\hline All & 392 & 62.0 & 9.4 & 18.1 & 8.2 & 2.3 & \\
\hline \multicolumn{8}{|l|}{ Gender } \\
\hline Boys/men & 193 & 53.4 & 13.0 & 21.8 & 10.4 & 1.6 & $* *$ \\
\hline Girls/women & 199 & 70.4 & 6.0 & 14.6 & 6.0 & 3.0 & \\
\hline \multicolumn{8}{|c|}{ Age groups (years) } \\
\hline $16-19$ & 109 & 57.8 & 13.8 & 19.3 & 6.4 & 2.8 & NS \\
\hline $20-22$ & 158 & 62.7 & 8.2 & 17.1 & 10.1 & 1.9 & \\
\hline $23-24$ & 124 & 64.5 & 7.3 & 18.5 & 7.3 & 2.4 & \\
\hline \multicolumn{8}{|l|}{ Sexual debut } \\
\hline After 2002 & 311 & 61.1 & 10.3 & 17.7 & 8.4 & 2.6 & NS \\
\hline 2002 or earlier & 77 & 64.9 & 7.8 & 16.9 & 7.8 & 2.6 & \\
\hline \multicolumn{8}{|c|}{ Number of sex partners in total } \\
\hline $1-3$ & 189 & 69.8 & 11.6 & 12.7 & 4.2 & 1.6 & $*$ \\
\hline $4-7$ & 102 & 55.9 & 7.8 & 23.5 & 11.8 & 1.0 & \\
\hline $8+$ & 79 & 57.0 & 7.6 & 21.5 & 10.1 & 3.8 & \\
\hline \multicolumn{8}{|l|}{ Coital frequency } \\
\hline Monthly & 268 & 78.7 & 6.0 & 9.3 & 4.9 & 1.1 & $* * *$ \\
\hline Less frequent & 100 & 22.0 & 15.0 & 41.0 & 17.0 & 5.0 & \\
\hline
\end{tabular}

* $P>0.05$, ** $P<0.01, * * * P<0.001$

Tested for statistically significant differences between the groups by means of Chi-square test NS Non significant

motivations and mechanisms that underlie these behaviours have important implications for preventive efforts.

In a recent web panel study among 18-24 year-old Norwegians, about 60\% reported using condoms during their first intercourse (Træen et al. 2011). Young men and women who used contraception upon first sexual intercourse are likely to continue using contraception thereafter (Træen et al. 2002, 2011), but they switch from using condoms to hormonal contraception after having been coitally active for some time (Træen et al. 1992, 2011). Accordingly, in Norway 2009, for the age group $18-24$, condom use was reported by $31 \%$ of males and $24 \%$ of females during the most recent sexual intercourse, while hormonal contraception was used by $49 \%$ of the men's partner and $57 \%$ of the female's.

The purpose of this paper is to explore the use and non-use of condoms among young heterosexual adults in Norway. To what extent do young heterosexual men and women use condoms and other types of contraception, and in which contexts does such use take place? What are the motives underlying both use and non-use of condoms, and how do the use and accompanying motives vary according to gender, age, sexual habits, and relationship with one's partner? 
Table 2 Use of condoms during the first sexual intercourse with the most recent sex partner, by selected social background variables (percent)
$* P>0.05, * * * P<0.001$

Tested for statistically significant differences between the groups by means of Chisquare test

NS Non significant

\begin{tabular}{|c|c|c|c|}
\hline Weighted data & $N$ & $\begin{array}{l}\text { Percentage of } \\
\text { condom users }\end{array}$ & Sign \\
\hline All & 393 & 50.1 & \\
\hline \multicolumn{4}{|l|}{ Gender } \\
\hline Boys/men & 193 & 56.0 & \multirow[t]{2}{*}{$*$} \\
\hline Girls/women & 200 & 44.5 & \\
\hline \multicolumn{4}{|c|}{ Age groups (years) } \\
\hline $16-19$ & 110 & 52.7 & \multirow[t]{3}{*}{ NS } \\
\hline $20-22$ & 157 & 50.3 & \\
\hline $23-24$ & 124 & 47.6 & \\
\hline \multicolumn{4}{|c|}{ Relationship with partner } \\
\hline Sweetheart & 243 & 50.6 & \multirow[t]{5}{*}{ NS } \\
\hline Ex-sweetheart & 38 & 52.6 & \\
\hline Friend & 70 & 45.7 & \\
\hline Casual & 32 & 56.3 & \\
\hline Other & 9 & 44.4 & \\
\hline \multicolumn{4}{|c|}{ Time of coital debut } \\
\hline After 2002 & 311 & 52.7 & \multirow[t]{2}{*}{$*$} \\
\hline 2002 or earlier & 76 & 39.5 & \\
\hline \multicolumn{4}{|c|}{ Number of sex partners in total } \\
\hline $1-3$ & 189 & 62.4 & \multirow[t]{3}{*}{$* * *$} \\
\hline $4-7$ & 103 & 35.0 & \\
\hline $8+$ & 79 & 44.3 & \\
\hline \multicolumn{4}{|l|}{ Coital frequency } \\
\hline Monthly & 269 & 48.3 & \multirow[t]{2}{*}{ NS } \\
\hline Less frequent & 100 & 55.0 & \\
\hline
\end{tabular}

\section{Methods}

\section{Participants}

On behalf of the Directorate of Health in Norway, the poll organisation Synovate conducted a nationwide survey on sexuality, including a "special survey" on the use of contraception, among a random web sample of 16-24 year-olds. The survey was conducted from May 8 to June 15, 2009.

Initially, a random sample of 16-24 year-olds was selected from Synovate's e-panel. Additionally, extracts from special subgroups (stratification) within the same e-panel were included to achieve the most representative nationwide sample of young people aged 16-24 years (stratification with regard to gender, age, and county). Two reminders were sent to the individuals in the selected sample.

A total of 3,189 persons were invited to participate in the survey. Of this targeted population, 871 participants completed the questionnaire, yielding a response rate of $27.3 \%$, which confirmed Synovate's expectation that the response rate among 16-24 year-olds would be lower than the average rate for the general population. 


\section{Procedure}

The survey was conducted via the Internet. Emails were sent to individuals drawn from Synovate's e-panel, with an invitation to participate in a confidential sexual behaviour survey. Synovate's e-panel consists of over 67,000 people who have agreed to participate in different types of surveys. All participants in the e-base were initially recruited through Synovate's nationwide representative surveys either by phone, face-face, or via postal interviews. Self-recruitment was not an option as this would increase the risk of bias. Synovate's e-panel is representative of the Norwegian Internet population. In 2009, 89\% in the age group 16-24 years reported daily Internet use (Statistics Norway 2010). There is good reason to assume that the proportion of 16-24 year-olds who have access to the Internet is particularly high.

The sample for the present study was selected in two stages. The main sample of 2,500 persons was drawn as a stratified group of randomly-selected individuals within each stratum in order to create a national representation within the target audience. During the data collection period, the net sample was controlled with regard to gender, age, and geography. These background variables were then compared with official statistics. Based on this result, an additional 689 individuals were selected to reach quotas set for particular age and gender groups.

There is little reason to believe that the choice of the Internet as the method of data collection has led to selection bias in this study. On the contrary, given the study target group, and the potentially sensitive issues sexuality encompasses, there is reason to believe that filling in the questionnaire on the Internet is particularly well-suited for data collection, when compared to alternative methods such as telephone and self-administered postal questionnaires.

For ethical reasons, and to minimize the risk of drop-out, participants were given the opportunity to skip questions they felt were too sensitive to answer.

\section{Statistical Analysis}

The statistical analysis was carried out employing SPSS version 15.0 for Windows.

\section{Results}

\section{The Most Recent Partner}

The respondents were asked where they had met their most recent sex partner. It was most commonly reported that the partner had been introduced via 'friends or family' (41\%), 'school or the workplace' (37\%), 'a private party' (18\%), 'a disco, bar or restaurant' $(15 \%)$, 'other place' $(9 \%)$, or 'the Internet' $(8 \%)$.

In most cases (see Table 1) the sex partner was most commonly referred to as 'a sweetheart' (62\%), followed by 'a friend I have sex with' (18\%), 'ex-sweetheart' $(9 \%)$, 'casual contact' $(8 \%)$, or 'other' $(2 \%)$. More young women $(70 \%)$ than men $(53 \%)$ reported having had sex with their sweetheart, and more men $(22 \%)$ than women $(15 \%)$ claimed they'd had sex with a friend $(P<0.01)$. Likewise, more of the 
respondents who'd had 1-3 partners in their lifetime had had sex with a sweetheart (vs. those with more than 3 partners), and more of those with $\geq 4$ partners (vs. fewer) had had sex with a friend $(P<0.05)$. Lastly, it was most common among those with a monthly coital frequency to have had sex with a sweetheart, and most common among those with less frequent coital frequency to have had sex with a friend $(P<0.001)$.

\section{The Use of Condoms During First Intercourse with the Most Recent Sex Partner}

A total of $50 \%$ of the respondents claimed they had used condoms during the first sexual intercourse with their most recent partner (Table 2). Significantly more men $(56 \%)$ reported having used condoms during first intercourse with the most recent partner than did women $(45 \%)(P<0.05)$. Similarly, a higher percentage of those who made their coital debut after $2002(53 \%)$ than of those who'd debuted in 2002 or earlier $(40 \%)(P<0.05)$, and more of those with 3 sex partners or less $(62 \%)$ than of those with $4-7$ partners in their life $(35 \%)(P<0.001)$ reported having used condoms during first intercourse with the most recent partner $(P<0.05)$.

The respondents were presented with eight different statements regarding motives for not using condoms on the particular occasion when they had sex for the first time with their most recent partner. They were asked to evaluate each statement on a 5-point scale from $1=$ 'corresponds very well to me', to $5=$ 'does not correspond to me'. In relation to motives for not having used condoms during first intercourse with the most recent partner, the statements respondents agreed to most were: 'I trust the partner' (mean 1.8; SD 1.0) and 'I had other contraception' (mean 1.9; SD 1.3). The statements they disagreed with most were that the partner would think they had an STI they did not want to reveal (mean 4.4; SD 0.9), or that they were not interested in building a relationship with him/her (mean 4.4; SD 0.8). Statistically significantly more young men than women agreed to the statements that the partner would think they had had many prior sex partners (mean 4.1; SD 1.0 and mean 4.4; SD 0.9, respectively), the partner would think they had an STI they did not want to reveal (mean 4.2; SD 1.0 and mean 4.5; SD 0.8, respectively), or that he/she would think they were only after sex (mean 4.0; SD 1.0 and mean 4.3; SD 1.8, respectively) (all $P<0.05$ ). There were no differences in the reporting according to age, coital debut, number of sex partners, or coital frequency.

To study the dimensional motives for not having used condoms during first sexual intercourse with the most recent partner, a factor analysis with varimax rotation was performed. Two dimensions of motives were identified, explaining $60.5 \%$ of the total variance (Table 3 ).

The variables that loaded highest on Factor 1 were 'if I introduce a condom the partner will think I have had many prior sex partners' (0.86), 'if I introduce a condom the partner will think I'm hiding a sexually transmitted disease' $(0.84)$, 'if I introduce a condom the partner will think I'm not interested in a relationship with him/her' (0.83), 'if I introduce a condom the partner will think I am only out for sex' (0.76), and 'if I introduce a condom the sex will be less romantic' (0.68). On this background, Factor 1 was called 'Fear of Suspicion'. Three variables loaded highest on Factor 2; 'condoms are not necessary because I already know the partner' $(0.80)$, 'I trust the partner' (0.78), and 'we have other contraception' (0.60). Factor 2 was 
Table 3 Dimensions of reasons for not using condoms during the first intercourse with the most recent sex-partner (factor analysis with varimx rotation; $n=191$ )

\begin{tabular}{lcc}
\hline & $\begin{array}{l}\text { Factor 1 (fear } \\
\text { of suspicion) }\end{array}$ & $\begin{array}{l}\text { Factor 2 } \\
\text { (mutual trust) }\end{array}$ \\
\hline Partner will think I have had many partners before him/her & 0.86 & -0.08 \\
Partner will think I have an STI that I'm not telling about & 0.84 & -0.04 \\
Partner will think I'm not interested in a relationship & 0.83 & -0.05 \\
Partner will think I'm only after the sex & 0.76 & 0.04 \\
Sex will become unromantic & 0.68 & 0.03 \\
I knew the partner before-hand & 0.16 & 0.80 \\
I trust the partner & -0.14 & 0.78 \\
We had other contraception & -0.05 & 0.60 \\
Eigenvalue & 3.2 & 1.6 \\
Percent of variance & 40.2 & 20.3 \\
\hline
\end{tabular}

subsequently baptized 'Mutual Trust'. The factors were saved as new variables based on their factor loadings.

To study the relationship between the 2-D of reasons for not using condoms and a set of predictor variables, multiple linear regression analyses were performed. The included predictors were gender, age, number of years coitally active, number of sex partners in one's life, and coital frequency during the past 12 months. None of the predictor variables had a statistically significant relationship with "Fear of Suspicion". 'Mutual Trust' had a statistically significant relationship with coital frequency $(\beta=0.21 ; P<0.01)$ and number of years coitally active $(\beta=0.25$; $P<0.05)$. Mutual trust in the sexual situation was higher among those who had been coitally active for a longer period of time, compared to a shorter period, and higher in those who had a coital frequency less than monthly.

\section{Use of Protection During the Most Recent Sexual Intercourse}

The most commonly reported motives for the most recent sexual intercourse were: 'sexually aroused' (78\%), 'in love' (66\%), 'partner wanted to' (30\%), 'curiosity/ excitement' (15\%), 'other reasons' (7\%), and 'it just happened' (3\%). None of the respondents reported having been pressured. More young women (73\%) than men (58\%) reported having been 'in love' $(P<0.01)$, and more men $(45 \%)$ than women $(17 \%)$ reported they'd had sex because 'the partner wanted to' $(P<0.001)$. Seventy-four percent of those who had had 1-3 partners in their lifetime reported having been 'in love', compared to $60 \%$ of those with a higher number of partners $(P<0.05)$. Lastly, strong motivations among those who had sex monthly were 'love' (77\%, $P<0.01$ ), and 'partner wanted to' ( $34 \%, P<0.05$ ), while those who had sex less frequently reported 'love' and 'partner wanted to' at just 36 and 23\%, respectively. It was more commonly reported that "it just happened" among those who had coitus less than once a month (9\%), as opposed to $1 \%$ among those who had sex monthly. 


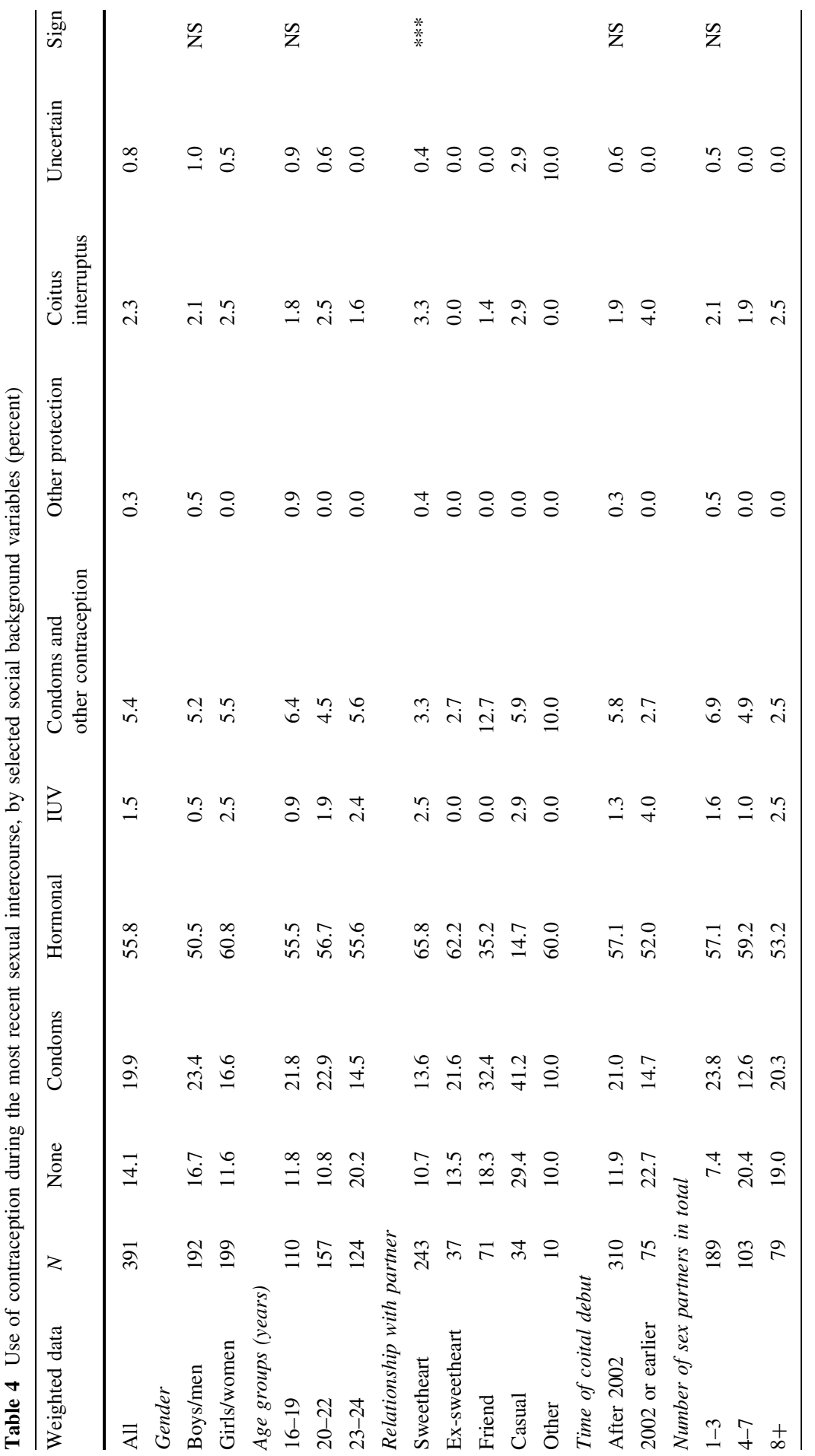

\section{Springer}




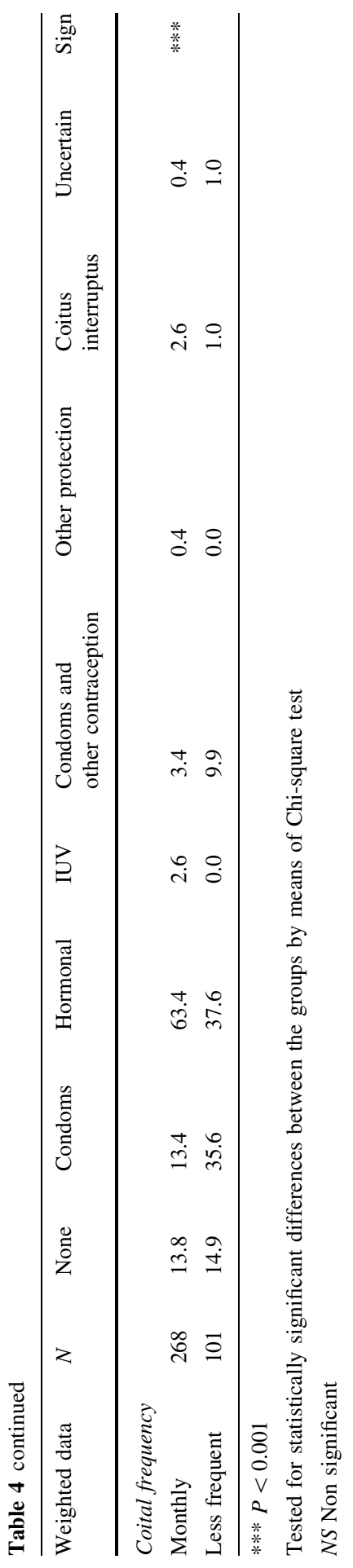




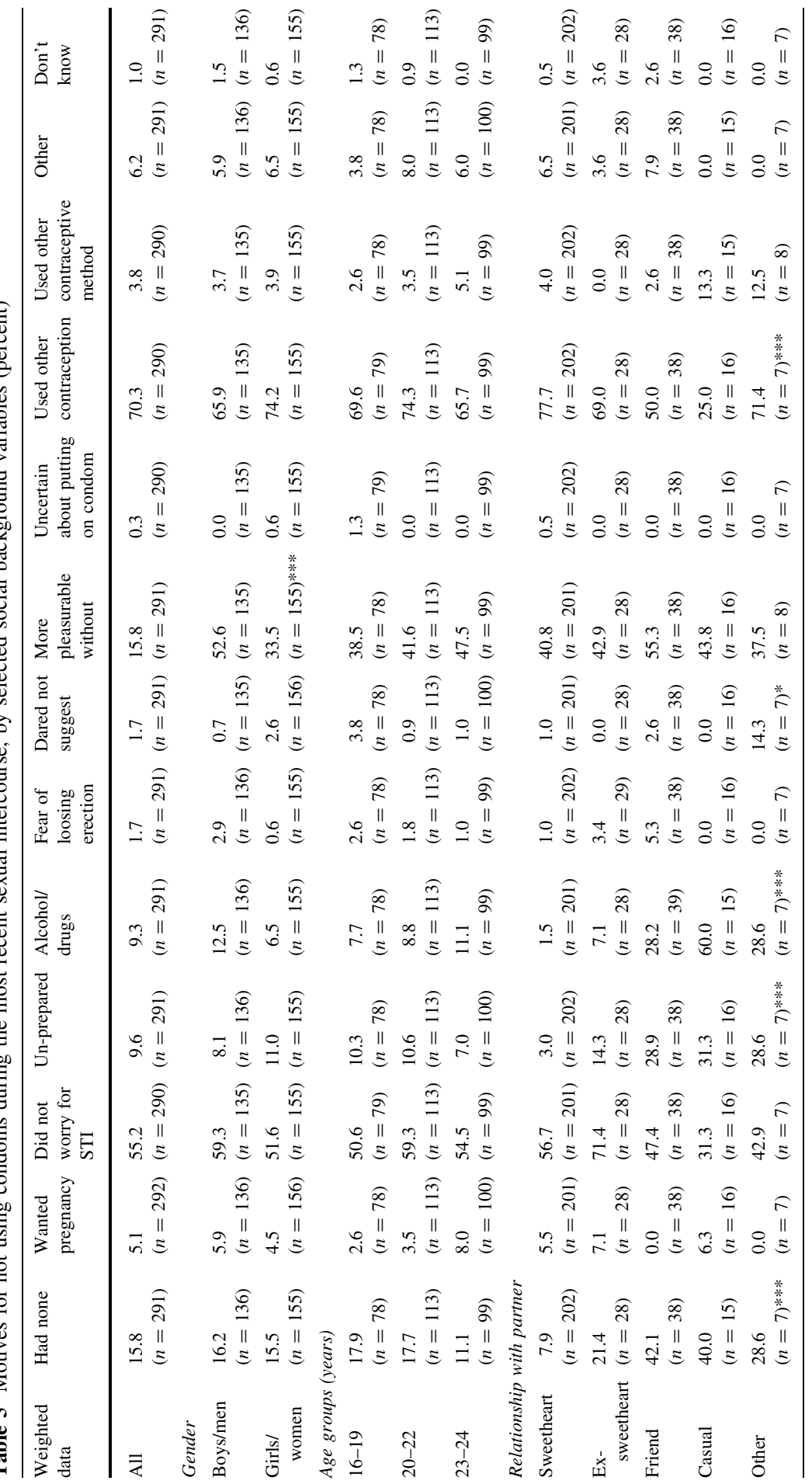




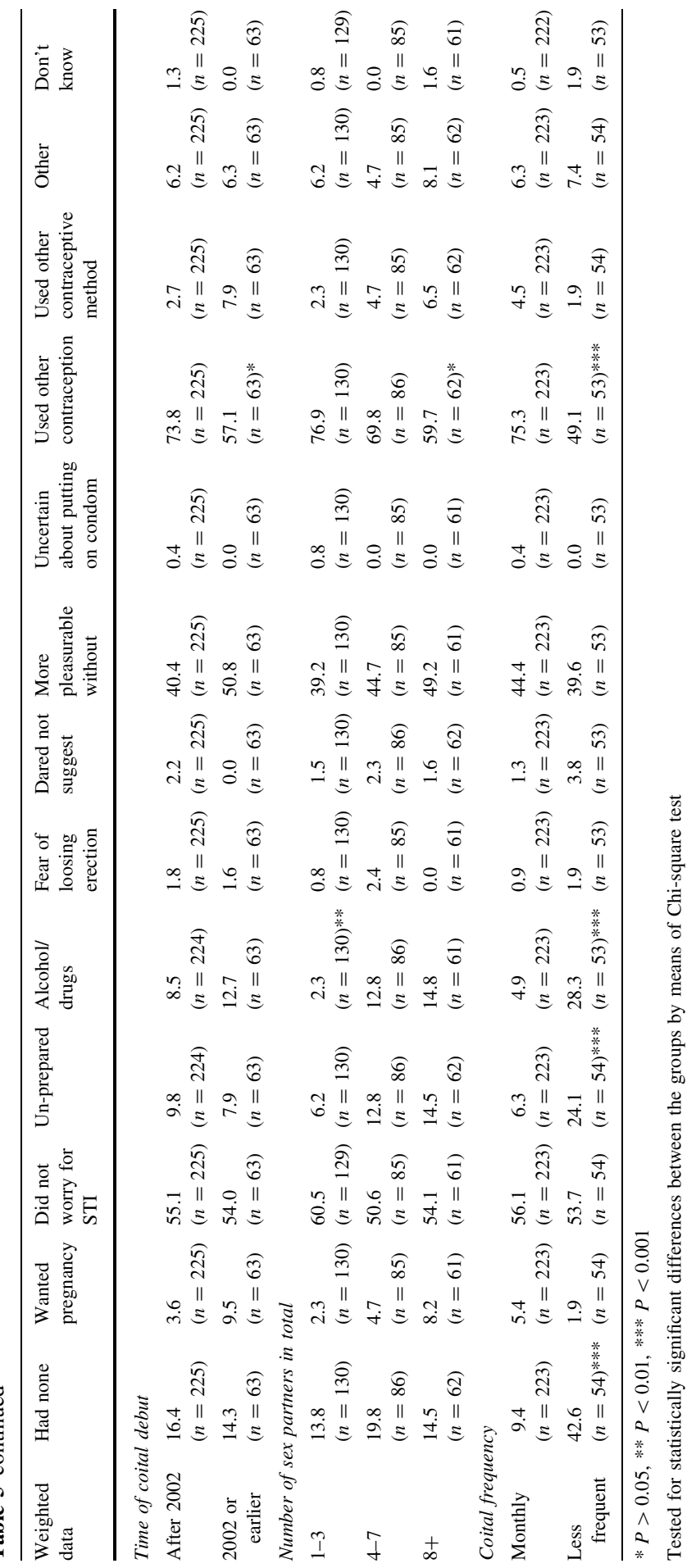




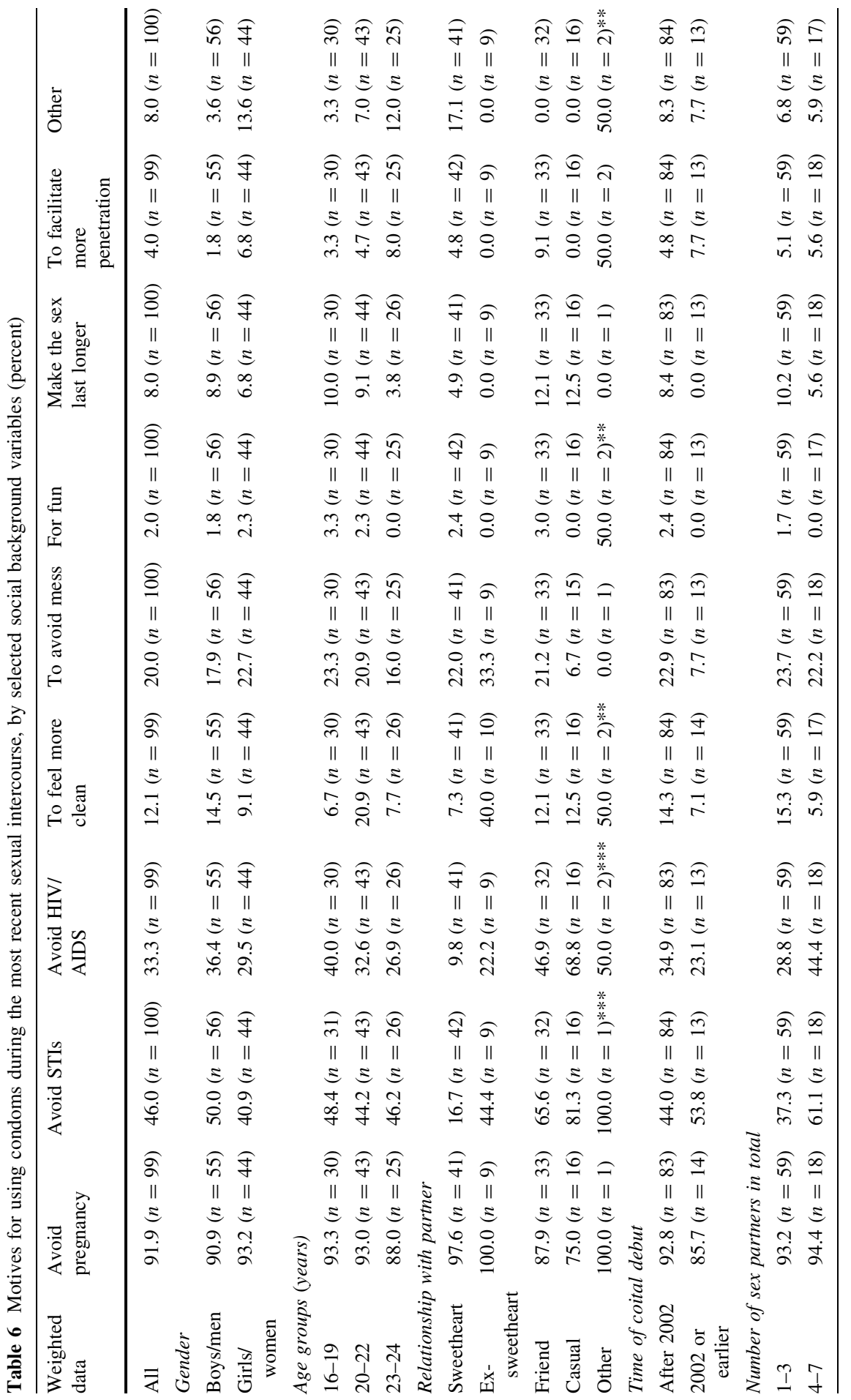




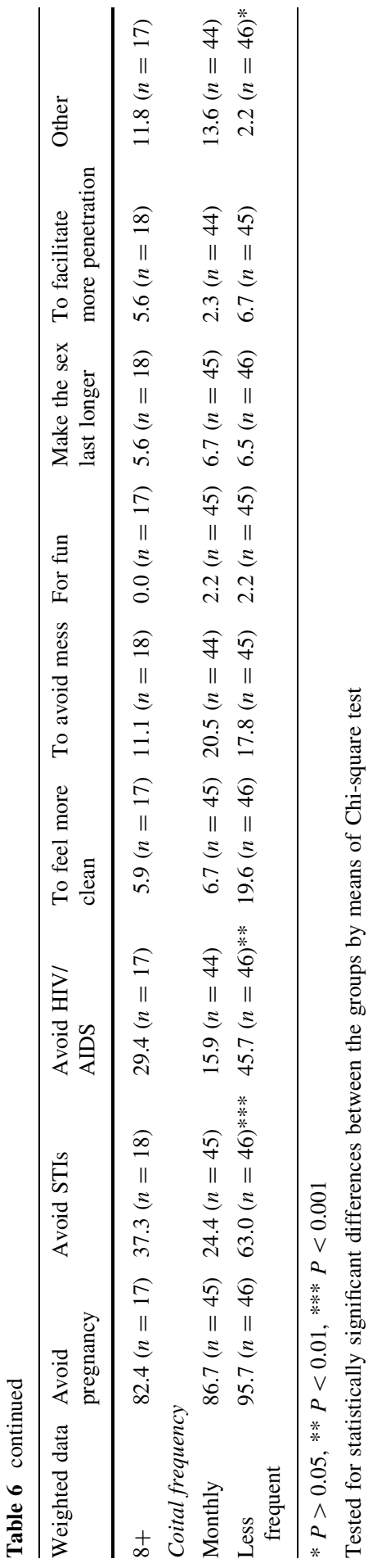


During the most recent intercourse, $56 \%$ of young adults reported using hormonal contraception, $20 \%$ used condoms, $14 \%$ did not use any contraception, $5 \%$ said they used condoms in addition to other contraception, $2 \%$ said 'coitus interruptus' or IUD, and $1 \%$ was uncertain (Table 4). There were statistically significant differences in the reporting only according to coital frequency and relationship with the partner. For those who had had sex with a casual partner, it was most common not to have used any kind of contraception (29\%). Hormonal contraception was most commonly reported by those who'd had sex with a sweetheart or an ex-sweetheart. The use of condoms was reported by $41 \%$ of those who' $d$ had sex with a casual partner, $32 \%$ of those who'd had sex with a friend, $22 \%$ of those whose partner had been an ex-sweetheart, and 14\% of those who'd had sex with their sweetheart $(P<0.001)$.

A total of $63 \%$ of young adults who had sexual intercourse monthly reported having used hormonal contraception, compared to $38 \%$ of those with a less frequent coital activity. In the later group 36\% reported having used condoms. There were no significant differences in the reporting according to gender, age, number of coital partners in life, and time of coital debut.

The respondents who did not report condom use during the most recent sexual intercourse were asked why they did not use any (Table 5). The most frequently reported reasons were: 'used other types of contraception' (70\%), 'did not worry about STIs' (55\%), 'more pleasurable without condoms' and 'had none available' (both 16\%), and 'was unprepared for intercourse' (10\%).

More young men than women reported that sex is more pleasurable without condoms (53 and 34\%, respectively). The relationship to the partner was strongly associated with use of contraception. In those who had interacted with their sweetheart, a condom was most often not used because they had used other contraception (78\%). This motive was valid only among $25 \%$ of those who had had sex with a casual partner. Among all those who had not had sex with their sweetheart, it was more common to report: 'had no condoms', 'was unprepared for intercourse', 'used alcohol or drugs', and 'didn't dare to suggest it'. More of those who made their sexual debut after 2002 (74\%) reported having used other kinds of contraception, compared to 57\% among those who'd debuted prior to 2002. However, this reason for lack of condom use was less common among those with a higher number of lifetime partners and less frequent coital frequency. More of those who had coitus less frequently reported that they'd had no condom, had used alcohol or drugs, and were unprepared for the sexual situation, when compared to those who had coitus at least monthly.

The most important reasons for having used condoms during the most recent intercourse were (Table 6): 'to avoid pregnancy' (92\%), 'to avoid STIs' (46\%), 'to avoid HIV/AIDS' (33\%), 'to avoid a mess' (20\%), 'to feel more clean' (12\%), 'to make sex last longer' and 'other' (both $8 \%$ ), 'to facilitate penetration' (4\%), or 'for fun' (2\%). Avoiding STIs and HIV was more often reported by those who had had sex with a casual partner or a friend than by those who'd had sex with a sweetheart. The same trend was observed among those who had sex less frequently, compared to those who had sex monthly. There were no significant differences in the reporting according to gender, age, number of coital partners in one's life and time of coital debut. 


\section{Discussion}

In this study we found that $56 \%$ reported using hormonal contraception and $20 \%$ used condoms during the most recent intercourse. A recent study among Croatian 18-24 year-olds showed that $52 \%$ of reported condom use and $11 \%$ relayed on the pill during the most recent intercourse (Štulhofer et al. 2009). Less recent studies have also shown significant differences between young adults in European countries in the use of contraceptive methods (Bajos et al. (2003). To the best of our knowledge, updated studies of use of contraceptive methods in Europe are sparse. Therefore, it is difficult to compare the results from this study to the findings from other European studies. A comparison of use of condoms and hormonal contraception between young adults in Norway and in other European countries, and the US, is also difficult due to differences in age and gender composition of the samples, as well as how use of contraception was measured (Avery and Lazdane 2008; Batár and Sivin 2010). Skouby (2010) found that 45\% 20-29 year-old European women used oral contraception, and $24 \%$ used condoms. The use of oral contraception was most widespread in the United Kingdom, France, and Germany, whereas the condom was most popular in Italy and Spain. The findings from this study confirm the preference for hormonal contraception in the north of Europe. As regards the use of condoms, every second participant reported using them during the first intercourse with their most recent partner. Furthermore, young Norwegian adults are shown to use more condoms with casual partners than young Croatian adults (Træen et al. 2011). This is more optimistic with regard to STI protection than what has been found previously in Norway (Træen et al. 2003a), and an increased trend in use of condoms corresponds well to what is found in other Western-European countries and the US (Batár and Sivin 2010).

Before discussing the major findings from this study, we choose to address some of its limitations. Firstly, the use of web samples in sexual behaviour research represents a new trend in Norway, and it is therefore difficult to know the extent to which this sample reflects the general population of 16-24 year olds. According to Statistics Norway (2010), 89\% of the age group 16-24 years report daily Internet use. There is good reason to assume that the proportion of 16-24 year-olds who have access to the Internet is particularly high. In this sense the web sample may well reflect the general population of young adults in Norway. On the other hand, it is not clear what type of population is represented in a sample with a response rate of $27 \%$. We have no definitive knowledge of the reasons for not wanting to participate in the study. One reason may be that the study was conducted during the prime exam period for students in high schools and universities in Norway. However, the critical issue is whether or not non-participation was related to patterns of sexual behaviour.

Stigum (1997) carried out a supplementary study to determine whether respondents and non-respondents in the Norwegian sexual behaviour study of 1992 had different patterns of sexual behaviour. He found that non-response was not associated with differences in sexual behaviour. This finding is supported by the findings from other Nordic surveys, which have shown that non-response is fairly random with respect to sexual behaviour (Kontula and Haavio-Mannila 1995; 
Lewin et al. 2000; Haavio-Mannila and Kontula 2003). Although it cannot be concluded from this that the non-respondents have severely different sexual behaviour patterns from the respondents, refusal to participate may just as well be related to attitudes, values, or moral issues. To summarize, it is not likely that the sample is severely biased. It is also assumed that non-response is not severely biased with regard to sexual behaviour, allowing us to weight the data during analysis. To conclude, we believe that the findings from this study can be generalized to the Norwegian web population in the ages 16-24 years old.

Returning to the scope and the findings in the study, we set out to explore circumstances around the use and non-use of condoms among young heterosexual adults in Norway. For the majority of our participants, sexual intercourse is taking place with a partner they feel socially and psychologically secure with. In the context of this frame it is reasonably concluded that the results unanimously show that adolescents in Norway 2009 are concerned with protecting themselves against unwanted pregnancy when they interact sexually, while they are not concerned about contracting STIs. This conclusion confirms previous conclusions on use of condoms in Norway (Træen 1993; Træen and Hovland 1998; Træen et al. 2002). As a consequence, health educators who attempt to encourage young adults to use STI protection are still trying to change the perception of what is "normal" and "natural" sexual behaviour. People "naturally" assume they are fecund and, if pregnancy is not the goal, they are expected to act responsibly and use contraception. The use of contraception is not socially stigmatized and is not perceived as threatening to either partner's self-perception. It is "normal" to use contraception. However, based on their behaviour, young adults rarely seem to accept as "natural", or consider the possible risk that they or their partner may be carrying an STI. This point is elucidated in this study, where mutual trust and fear of suspicion were the underlying motives for not using condoms during the first intercourse with the most recent partner. Fertility is seen as "natural", while there is nothing "natural" about STIs. To base one's behaviour in a sexual context on an assumption that it is "natural" to take precautions against STIs would most likely be received by the partner as an instance of being "unnaturally" suspicious.

In conclusion, people's perception of what is "normal" and "natural" conduct in a sexual context seems to have changed little during the past 2-3 decades (Træen 1993). This implies that what sexual health educators are still attempting to change in condom campaigns to prevent STIs and HIV is in fact the perception of what is "normal" and "natural" in life. Norwegians have fairly positive attitudes towards condoms and good knowledge of the dangers associated with unprotected sex and STI/HIV (Mandal et al. 2008). Thus, this does not stop them from using condoms in potentially risky sexual contexts. With regard to the use of measures to prevent unwanted pregnancy, there are clear indications that increasing the availability of such measures also increases the actual use (Træen et al. 2009; Træen and Gravningen 2010; Øren et al. 2010). From an STI preventive healthcare perspective, rather than targeting the individual through condom campaigns, it could be more beneficial to increase the availability of free condoms in public arenas where young adults socialize and meet their partners. It is likely that the presence of condoms would also send a signal to young adults that STI is an issue to consider even in a 
romantic context, and thereby perhaps increase the probability of actual condom use.

Open Access This article is distributed under the terms of the Creative Commons Attribution Noncommercial License which permits any noncommercial use, distribution, and reproduction in any medium, provided the original author(s) and source are credited.

\section{References}

Agenda. (2008). Evaluering av nasjonal ordning med gratis kondomer. Rapport til Helsedirektoratet [evaluation of a national arrangement with free condoms]. Oslo: The Norwegian Directorate of Health.

Avery, L., \& Lazdane, G. (2008). What do we know about sexual and reproductive health of adolescents in Europe? The European Journal of Contraception and Reproductive Health Care, 13, 58-70.

Bajos, N., Guillaume, A., \& Kontula, O. (2003). Reproductive health behaviour of young Europeans (Vol. 1). Strasbourg: Council of Europe Publishing.

Batár, I., \& Sivin, I. (2010). State-of-the-art of non-hormonal methods of contraception: I. Mechanical barrier contraception. The European Journal of Contraception and Reproductive Health Care, 15, 67-88.

Haavio-Mannila, E., \& Kontula, O. (2003). Sexual trends in the Baltic Sea area. Helsinki: Publication of the Population Research Institute.

Helmius, G. (1990). Mogen för sex?! Det sexuellt restriktiviserande samhället och ungdomars heterosexuella glädje. [Mature enough for sex?! The sexually restrictive society and adolescents' heterosexual joy]. Uppsala: University of Uppsala.

Kontula, O., \& Haavio-Mannila, E. (1995). Sexual pleasures. Enhancement of sex life in Finland, 1971-1992. Brookfield, VT: Dartmouth Publishing Company.

Lewin, B. (1987). Att se sexualiteten. Om sexuall socialisation, förhållningssätt ochsexuella erfarenheter bland människor med medfödda funktionshinder [To see the sexuality. Sexual socialization, beliefs and practices among handicapped people]. Uppsala: University of Uppsala.

Lewin, B. (1990). Potentials for change. Scaninavian Journal of Infectious Diseases, 69, 199-205.

Lewin, B., \& Helmius, G. (1983). Ungdom och sexualitet; En sociologisk studie av ungdoms sexuella föreställingar och erfarenheter [Youth and sexuality: a sociological study of young people's sexual conceptions and experiences, Swedish text]. Uppsala: Uppsala University Press.

Lewin, B., Fugl-Meyer, K., Helmius, G., Lalos, A., \& Månsson, S. A. (2000). Sex in Sweden. On the Swedish sexual life. Stockholm: National Institute of Public Health.

Mandal, R., Nuland, B. R., \& Grønningsæter, A. B. (2008). Fortsatt farlig a kysse? Kunnskap om og holdninger til hiv [Still dangerous to kiss? Knowledge of and attitudes towards HIV]. Fafo-rapport 2008:21. Oslo: FAFO.

Øren, A., Leistad, L., \& Haugan, T. (2010) Endres prevensjonsvaner og abortrate hos kvinner 20-24 år ved tilbud om gratis hormonell prevensjon? [Does contraceptive habits and abortion rate in 20-24 year old women change as a result of offering free hormonal contracetion?]. SINTEF A14751: Åpen Rapport. Trondheim: SINTEF Teknologi og Samfunn Forebyggende helsearbeid.

Rosenthal, D., Gifford, S., \& Moore, S. (1998). Safe sex or safe love: Competing discourses? AIDS Care, $10,35-47$.

Skouby, S. O. (2010). Contraceptive use and behavior in the 21st century: A comprehensive study across five European countries. The European Journal of Contraception and Reproductive Health Care, 15(S2), S42-S53.

Statistics Norway (2010). Media use, book reading, library visits. Retrieved April 10 2010, from http://www.ssb.no/english/subjects/07/02/30/main.html.

Stigum, H. (1997). Mathematical models for the spread of sexually transmitted diseases using sexual behaviour data. Norwegian Journal of Epidemiology, 7(Suppl. 5).

Stigum, H., Magnus, P., Veierød, M., \& Bakketeig, L. S. (1995). Impact on STI spread of increased condom use by young females, 1987-1992. International Journal of Epidemiology, 24, 813-820. 
Štulhofer, A., Graham, C., Božičević, I., Kufrin, K., \& Ajduković, D. (2009). An assessment of HIV/STI vulnerability and related sexual risk-taking in a nationally representative sample of young croatian adults. Archives of Sexual Behavior, 38, 209-225.

The National Institute of Public Health (2008). Norwegian prescription database 2004-2007. Oslo: The National Institute of Public Health. Retrived from the Internet. April 20th http://www.fhi.no/eway/ default.aspx?pid=233\&trg=MainLeft_5583\&MainArea_5661=5583:0:15,1134:1:0:0::00:0\& MainLeft_5583=5603:70802::1:5585:1::0:0.

Træen, B. (1993). Norwegian adolescents' sexuality in the era of AIDS. Empirical studies on heterosexual behaviour. Thesis. Oslo: University of Oslo.

Træen, B., \& Hovland, A. (1998). Games people play. Sex, alcohol and condom use among urban Norwegians. Contemporary Drug Problems, 25, 3-48.

Træen, B., \& Gravningen, K. (2010). First sexual intercourse in Norway 2009. Paper presented at the 10th congress of the European federation of sexology, Porto, 09-13 May.

Træen, B., Lewin, B., \& Sundet, J. M. (1992). Use of birth control pills and condoms among 17-19 years old adolescents in Noway. Contraceptive versus protective behaviour? AIDS Care, 4, 371-380.

Træen, B., Stigum, H., \& Eskild, E. (2002). Contraception and STI protection among urban Norwegians. Culture, Health and Sexuality, 4, 85-102.

Træen, B., Stigum, H., \& Magnus, P. (2003a). Rapport fra seksualvaneunders $\phi$ kelsene i 1987, 1992, 1997 og 2002 [report from the sexual behaviour surveys in 1987, 1992, 1997 and 2002]. Oslo: National Institute of Public Health.

Træen, B., Stigum, H., Hassoun, J., \& Zantedeschi, E. (2003b). Presexual alcohol consumption and use of condoms: A cross-cultural European study. Culture, Health and Sexuality, 5, 439-455.

Træen, B., Stigum, H., \& Myrberg, A. J. (2009). Condom use and use of contraceptive measures among Norwegians 2002-2008. Poster presented at the 19th WAS World congress for sexual health, Gøteborg, Sweden, 21-25 June.

Træen, B., Stulhofer, A., \& Landripet, I. (2011). Young and sexual in Norway and Croatia: Revisiting the Scandinavian versus Mediterranean gendered pattern of sexual initiation. International Journal of Sexual Health (in press). 